\title{
Point-of-care ultrasound use in pediatric intensive care units in Turkey
}

\author{
Nagehan Aslan ${ }^{\oplus}$, Dincer Yildizdas ${ }^{\oplus}$, Ozden Ozgur Horoz ${ }^{\oplus}$, Faruk Ekinci ${ }^{\oplus}$, \\ Turkish POCUS Study Group \\ Department of Pediatrics, Division of Pediatric Critical Care Medicine, Çukurova University Faculty of Medicine, Adana, Turkey.
}

\begin{abstract}
Background. Point-of-care ultrasound is commonly used in pediatric intensive care units in recent years. The aim of this study was to find an answer to the question "where are we now in Turkish pediatric intensive care units for point-of-care ultrasound use?".
\end{abstract}

Methods. This was a multicenter, descriptive study in which we developed an online survey. We asked 45 questions about point-of-care ultrasound using fields and training status of clinicians in pediatric intensive care units.

Results. A total of 29 units responded to the questions completely. Of all included units $41.4 \%$ were in public hospitals, 6.9\% in city hospitals (public-private partnership) and 51.7\% in university hospitals. The most common use of point-of-care ultrasound was central venous catheter insertion. Lung ultrasound use rates for detection of pleural effusion, evaluation of pneumothorax, and diagnosis of pneumonia were $93.1 \%, 86.2 \%$, and $34.5 \%$, respectively. Critical care echocardiography use rate was $79.3 \%$. In $89.7 \%$ of the units, intensive care specialists had been specifically trained for the use of point-of-care ultrasound.

Conclusions. Our study showed that point-of-care ultrasound was not only used for central venous catheterization but also for widespread fields in pediatric intensive care units. With an experienced team, it is possible to perform rapid, noninvasive and repeatable ultrasonographic assessment of patients. In our view point-of-care ultrasound is the new stethoscope of critical care physicians.

Key words: central venous catheter, echocardiography, intensive care unit, lung, point-of-care ultrasound.

Point-of-care ultrasound (POCUS) or critical care ultrasound is a bedside ultrasonographic assessment and is applied to patients by the clinician in charge. ${ }^{1}$ It provides rapid and real time answers about the clinical problems of patients. Use of bedside ultrasonography by clinicians other than radiologists is gradually becoming common. ${ }^{2}$ Pediatricians commonly use POCUS, especially in emergency and intensive care departments. In fact, POCUS has become a part of the physical examination of critically ill children in pediatric intensive care

\footnotetext{
$\bowtie$ Nagehan Aslan

nagehan_aslan@hotmail.com
}

Received 27th August 2019, revised 11th October 2019, accepted 22nd October 2019. units (PICUs) in recent years. ${ }^{3,4}$ Patients in PICUs frequently have critical problems and need quick assessments due to their hemodynamical instability. ${ }^{5}$ Through POCUS results, clinicians can manage treatment approaches. The most important advantages of this technique are that it is easy to use, repeatable, noninvasive, cheap, painless and radiation-free. ${ }^{6}$

Adult studies have shown improved clinical outcomes in patients with the use of POCUS. ${ }^{7}$ Clinicians can use POCUS with many aspects, such as critical care echocardiography to evaluate myocardial contractility and cardiac index measurements or to detect pericardial tamponade ${ }^{8}$, lung ultrasound to evaluate pneumothorax, pleural effusion and pneumonia9 ${ }^{9}$ ophthalmic ultrasound for the 
clinical follow-up of increased intracranial pressure with optic nerve sheath diameter (ONSD) measurements ${ }^{10}$, fast intraabdominal assessment to detect perihepatic or perisplenic hemorrhage $\mathrm{e}^{11}$, vascular ultrasound to insert central venous catheter or invasive arterial catheter $^{12}$, to measure vena cava inferior maximum and minimum diameters to evaluate the volume status of patients with vena cava inferior collapsibility index ${ }^{13}$ (spontaneous breathing patients) and vena cava inferior distensibility index (mechanically ventilated patients). ${ }^{14}$

In the world and in our country, most PICUs have POCUS technology, and the frequency of training courses intended for pediatric intensive care and emergency care specialists are increasing. ${ }^{15}$ There are many adult studies on POCUS use in intensive care units; however, in the pediatric field, the reports of pediatric emergency departments stand out. ${ }^{16}$ There is limited data available in the literature describing the status and fields of use of POCUS in PICUs.

The main purpose of our study was to analyze the use of POCUS in Turkish PICUs. We aimed to detect the common clinical applications of POCUS and the training status of pediatric intensive care specialists in tertiary PICUs at university and state hospitals in Turkey.

\section{Material and Methods}

We planned a multicenter, cross-sectional, descriptive study. We developed an online survey using theSurveyMonkey online platform, including 45 questions. The main topics of the survey were the descriptive characteristics of the hospital and the physician responding to the survey, features of the ultrasound machine, POCUS application fields and frequencies in the PICU and training status of the clinical staff including clinicians and nurses. The survey was distributed by the Turkish Society of Pediatric Emergency and Intensive Care to the clinical chiefs of PICUs via e-mail. The study protocol was approved by the local Ethical Committee of
Çukurova University Medical Faculty (March 2019; 86).

\section{Results}

\section{Characteristics of chief in charge for the survey and PICU's}

The survey reached 36 units, and 29 of them responded to the questions completely. Each survey was answered only once by each PICU and by the chief clinician of the department. The pediatric intensive care experience of the participant chief of the department was below 5 years in $48.3 \%(\mathrm{n}=14), 6-10$ years in $31.0 \%$ $(\mathrm{n}=9), 10-15$ years in $17.2 \%(\mathrm{n}=5)$ and above 15 years in $3.4 \%(n=1)$. Of all included PICUs, $41.4 \%(n=12)$ were in public hospitals, $6.9 \%(n=$ 2 ) in city hospitals (public-private partnership) and $51.7 \%(\mathrm{n}=15)$ in university hospitals. All participating PICUs only provided medical and post-surgery care for pediatric patients. The types of patients followed in PICUs are shown in Table I.

Of all units, $27.6 \%(\mathrm{n}=8)$ had fewer than 10 beds, $51.7 \%(\mathrm{n}=15)$ had $11-20$ beds, $13.8 \%(\mathrm{n}=4)$ had $21-40$ beds, and $6.9 \%(n=2)$ had more than forty

Table I. Types of patients followed in 29 pediatric intensive care units.

\begin{tabular}{lc}
\hline Type of patients & $\begin{array}{c}\text { Number }(\%) \\
\text { of PICUs } \\
\text { involved }\end{array}$ \\
\hline Multiple trauma & $22(75.9)$ \\
Medical & \\
$\quad$ Neuromuscular & $29(100.0)$ \\
Metabolic disorders & $28(96.6)$ \\
Gastroenterology & $25(86.2)$ \\
$\quad$ Endocrinology & $29(100.0)$ \\
$\quad$ Nephrology & $28(96.6)$ \\
Infectious diseases & $29(100.0)$ \\
Cardiac surgery & $16(55.2)$ \\
Neurosurgery & $24(82.8)$ \\
Extracorporeal membrane oxygenation & $14(48.3)$ \\
Transplant & $8(27.6)$ \\
Postoperative pediatric surgery & $26(89.7)$ \\
\hline
\end{tabular}

PICUs: pediatric intensive care units 
beds. As for the number of physicians on staff, $10.3 \%(n=3)$ of the units had more than eight physicians, $24.1 \%(n=7)$ had between five and eight and $65.5 \%(\mathrm{n}=19)$ had fewer than five.

\section{Status of ultrasound machine in PICU}

Of all the PICUs, $96.6 \%(n=28)$ had a dedicated ultrasound machine, and $41.4 \%(n=12)$ of those shared the ultrasound machine with other units in the hospital. Only one (3.4\%) of the units that responded to our survey had no ultrasound machine. Of the PICUs with ultrasound machines, $72.4 \%(\mathrm{n}=21)$ had portable systems, while $27.6 \%(n=8)$ had non-portable ones.

\section{Clinical use of POCUS}

A total of $55.2 \%(n=16)$ units reported clinical using of POCUS daily, $41.4 \%(n=12)$ of them every two or three days, $3.4 \%(n=1)$ weekly. In $72.4 \%(n=21)$ of the PICUs, more than $75 \%$ of the pediatric intensive care specialists regularly used POCUS for clinical assessment, and this frequency range changed between $50 \%$ to $\% 75$ in $14.2 \%, 25 \%$ to $50 \%$ in $3.5 \%$ and fell below $25 \%$ in $10.7 \%$. In $89.7 \%(n=26)$ of the PICUs, intensive care specialists had been specifically trained for the use of POCUS. All participants agreed on the clinical benefits of the use of POCUS for the assessment of critically ill children in PICUs. Table II shows the purposes and frequencies of use of POCUS. The most common use of POCUS was central venous catheter insertion $(\mathrm{n}=16 ; 55.2 \%)$. A total of $7(24.1 \%)$ units never used anatomical land-marks for catheterization and always inserted central venous catheter with real-time POCUS (internal jugular vein in $100 \%$, femoral vein in $62.1 \%$, subclavian vein in $13.8 \%$ ). Twelve units (41.4\%) used POCUS for arterial catheterization and two units always inserted the arterial line with POCUS. Fourteen units $(48.3 \%)$ reported that they never used POCUS for arterial line insertion. Critical care echocardiography use rate in PICUs was 79.3\% $(n=23)$ in our study (assessment of myocardial contractility in 59\%, cardiac output and cardiac index in $31 \%$, pericardial effusion in $93 \%$ ). The results of our survey showed that $31 \%$ of the
Table II. Purposes of point-of-care ultrasonography in pediatric intensive care units.

\begin{tabular}{|c|c|}
\hline Purposes & $\begin{array}{c}\text { Number (\%) } \\
\text { of PICUs } \\
\text { involved }\end{array}$ \\
\hline Critical care echocardiography & $23(79.3)$ \\
\hline Assessment of cardiac contractility & $17(58.6)$ \\
\hline Assessment of cardiac index & $9(31.0)$ \\
\hline $\begin{array}{l}\text { Management of cardiorespiratory } \\
\text { arrest }\end{array}$ & $16(55.2)$ \\
\hline Assessment of airway & $3(10.3)$ \\
\hline Assessment of nasogastric tube & $2(6.9)$ \\
\hline \multicolumn{2}{|l|}{$\begin{array}{l}\text { Assessment of intravascular blood } \\
\text { volume }\end{array}$} \\
\hline Vena cava inferior collapsibility index & $12(41.4)$ \\
\hline Vena cava inferior distensibility index & $8(27.6)$ \\
\hline Central venous catheter insertion & $16(55.2)$ \\
\hline Arterial catheterization & $12(41.4)$ \\
\hline Diagnosis of pneumothorax & $25(86.2)$ \\
\hline Diagnosis of pneumonia & $10(34.5)$ \\
\hline $\begin{array}{l}\text { Diagnosis and intervene of pleural } \\
\text { effusion }\end{array}$ & $27(93.1)$ \\
\hline Assessment of free intraperitoneal fluid & $21(72.4)$ \\
\hline Assessment of diaphragm paralysis & $13(44.8)$ \\
\hline Assessment of optic nerve & $9(31.0)$ \\
\hline
\end{tabular}

PICUs: pediatric intensive care units

units in our country used POCUS for ONSD measurements in patients with increased intracranial pressure. Twenty-four $(82.8 \%)$ of our participating specialists were trained by the Turkish Society of Pediatric Emergency and Intensive Care for POCUS use. In addition; the nurses in one of the participating units had training about ultrasound use for peripheral venous catheter insertion. Sixteen units (55.2\%) agreed on the necessity of nurse training.

\section{Discussion}

Use of POCUS has led to great advances in rapid and repeated evaluation and intervention of critically ill pediatric patients in PICUs. Day by day, the use of POCUS becomes an important skill for pediatric critical care medicine providers. ${ }^{17}$ Most adult studies have shown that POCUS use improves the clinical 
outcomes of critically ill patients and decreases mortality and morbidity. ${ }^{18}$ In recent years, most PICUs have acquired POCUS technology, and the training courses for pediatric intensive care specialists have become popular. ${ }^{15}$ The aim of our study was to detect the frequency of use and availability of POCUS and the specific training status of pediatric intensive care specialists in Turkish PICUs.

Echocardiography is becoming a standard of critical care in many intensive care units, and more clinicians are learning how to perform bedside critical care echocardiography techniques as more pediatric intensivist are becoming familiar with POCUS in PICUs. ${ }^{19,20}$ The echocardiography type referred to as critical-care echocardiography has become a part of the routine evaluation of patients in the PICU by pediatric intensivists. ${ }^{20,21}$ This noninvasive technique allows the intensivist to measure ejection fraction, cardiac output and cardiac index and to assess pericardial effusion and becomes a guide for the management of treatment and ensuring the hemodynamic stability of critically ill patients. ${ }^{21}$ The importance of cardiac index in guiding fluid and inotropic management in septic shock was emphasized in the recent clinical practice parameters published in 2017, which highlighted the significance of cardiac index measurement in the PICU.22 In another survey similar to our study, the results showed a $72.7 \%$ rate of POCUS use for the assessment of cardiac function. In the first national survey from the USA, Lambert et $a .^{23}$ reported a $37.5 \%$ rate of POCUS use for myocardial function. In our survey, the rate of critical care echocardiography use in Turkish PICUs was found to be $79.3 \%$ (assessment of myocardial contractility in $58.6 \%$, cardiac output and cardiac index in $31 \%$, pericardial effusion in $93.1 \%$ ).

Community-acquired and ventilator-associated pneumonia are common and important problems in PICUs. ${ }^{24,25}$ In addition, chest X-ray is still a widespread tool for the diagnosis of pneumonia. In the last years, most studies have shown that bedside lung ultrasound performed by pediatric critical care providers was highly accurate for the diagnosis of pediatric pneumonia. ${ }^{25}$ Lung ultrasound has proven useful for detecting lung abnormalities in adults, and recent studies have reported the usefulness of lung ultrasound in children with pneumonia and bronchiolitis. ${ }^{24,25}$ Furthermore, if you can use POCUS for the diagnosis of pneumothorax, intervention can be easy and rapid and can manage pleural effusion drainage with less complication and greater success. ${ }^{26-28}$ Besides, lung ultrasound allows the evaluation and drainage of pleural effusion, which is another useful aspect of lung ultrasound. The most important advantage of lung ultrasound is that it is a radiation-free technique. ${ }^{1,28}$ Cortes et al. ${ }^{29}$ reported POCUS use rates for pleural effusion, pneumothorax and other lung diseases such as pneumonia as $73.3 \%, 50 \%$ and $46.7 \%$, respectively. ${ }^{30}$ Our survey results showed that $93.1 \%$ of the units used POCUS to detect pleural effusion, $86.2 \%$ for the evaluation and intervention of pneumothorax, $34.5 \%$ for pneumonia diagnosis, $72.4 \%$ for the drainage of pleural effusion and $31 \%$ for the clinical followup of pneumonia in our country.

The use of POCUS decreases the risk of complication and the number of attempts in some procedures such as centralperipheral venous catheterization and arterial catheterization. It has been reported that the use of US guidance significantly improves the rate of successful peripheral intravenous access, especially in patients who are difficult to access and decreases the amount of time to perform the procedure, the number of percutaneous punctures and needle redirections compared to traditional approaches such as palpation and landmark guidance. ${ }^{30}$ Pediatric critical care nurses had training for ultrasound use for peripheric venous catheter insertion only in one of our participating units. We thought that this was a low ratio for our study, and when we asked about the necessity of POCUS training for nurses, nearly half of our participating units stated that they found this use of POCUS redundant. 
In pediatric emergency and intensive care departments, central venous catheter placement may be required in life-threatening conditions where fluid and drug resuscitation are needed or in complex patients with poor vascular access. Ultrasound-guided pediatric central venous catheterization has been shown to be superior to traditional landmark and palpation techniques. $^{31}$ A survey study reflecting the results of 128 PICUs in the USA showed that using POCUS for central venous catheterization was more common than peripheral or arterial catheter insertion and the internal jugular vein was the preferred initial site in their survey, similar to our results. ${ }^{23}$ The most common use of POCUS in our survey was central venous catheter insertion. Furthermore, $24.1 \%$ of the units never used anatomical land-marks for catheterization and always inserted central venous catheter with real-time POCUS.

Arterial catheterization, commonly used in infants and small children in intensive care units and operating rooms, can be technically challenging. ${ }^{32}$ Nevertheless, the ultrasoundguided technique improves the first-attempt success rate in both adults and children. ${ }^{33}$ The author of another survey study from Spain reported a POCUS use rate of $75 \%$ for arterial catheterization. ${ }^{29}$ The survey results showed that $41.4 \%$ of the units in our country used POCUS for arterial catheterization and 16.6\% of them always inserted the arterial line with POCUS.

One of the most important parts of POCUS for noninvasive and rapid assessment of fluid status in critically ill children is the measurements of vena cava inferior diameters. ${ }^{13}$ Vena cava inferior is a vessel that is highly sensitive to fluid changes, and the collapsible vessel varies in size with respiratory changes in intra-thoracic pressure. ${ }^{34}$ There is a vena cava collapsibility index for children with spontaneous breathing and a distensibility index for mechanically ventilated children. These features of inferior vena cava have allowed pioneering clinicians to measure both collapsibility indexes. ${ }^{35} \mathrm{We}$ asked about vena cava inferior maximum and minimum diameter measurements and vena cava inferior collapsibility index (children with spontaneous breathing) and vena cava inferior distensibility index (mechanically ventilated children) use for the management of fluid treatment, and the responses of participants showed that $43.4 \%$ of the units commonly used the collapsibility index and $27.6 \%$ commonly used the distensibility index in their units.

One such noninvasive modality includes the estimation of ONSD use in bedside ultrasounds. ${ }^{10}$ The optic nerve sheath is an anatomical extension of the dura mater, and the subarachnoid space around the optic nerve is continuous with the subarachnoid space. ${ }^{36}$ Due to this direct communication, pressure changes in the intracranial compartment are transmitted to the intra-orbital subarachnoid space around the optic nerve. Dilatation of the optic nerve sheath has been shown to be a much earlier manifestation of intracranial pressure rise..$^{37}$ It is not easy to take computed tomography or magnetic resonance images in a hemodynamically unstable patient. Ultrasound technology allows to take repeated and radiation-free images of the optic nerve sheath in patients with increased intracranial pressure at the bedside. ${ }^{38}$ The results of our survey showed that $31 \%$ of the units in our country used POCUS for ONSD measurements in patients with increased intracranial pressure.

The current cardiopulmonary resuscitation guidelines recommend performing POCUS when a reversible cause of cardiopulmonary arrest is suspected, although it is stated that improvement of outcomes with the use of POCUS in cardiopulmonary arrest has not been yet demonstrated. POCUS is helpful in cardiopulmonary resuscitation in diagnosing reversible causes of cardiac arrest. ${ }^{39}$ The rate of bedside ultrasound use for the efficacy of cardiopulmonary resuscitation was found to be $55.2 \%$ in our study.

Point-of-care ultrasound has been reported as a diagnostic tool for the confirmation of nasogastric tube placement for neonates and adults in the literature. ${ }^{40-42}$ The results of these 
studies showed a decreased need for abdominal radiography for nasogastric tube placement. Our results showed that $6.9 \%$ of our units sometimes use POCUS to verify nasogastric tube location.

In recent years, the training curricula for pediatric emergency care and critical care providers have gradually increased. The results of one study showed a high concordance between echocardiographic image quality and trained pediatric critical care providers and cardiologists. In the same study, Conlon et al. $^{42}$ detected significantly increased image interpretation ability in trained clinicians compared to the others. Most of the participants in our survey were trained in the course organized by the Turkish Society of Pediatric Emergency and Intensive Care. This provided a homogeneity for the fields of use of POCUS. We think that the rise of training courses is important for the common use of POCUS in PICUs.

Our study had some limitations. As with the other voluntary surveys, our results could not directly show the real frequency of use and likely only showed the views of those surveyed.

Inconclusion, POCUSis an important technology frequently used in most PICUs in Turkey. In our view, POCUS is the new stethoscope of critical care physicians. If you have POCUS and have an experienced team, you can perform fast, noninvasive and repeatable assessments with clinical changes of patients without the need for an external consultant. Our study shows that POCUS was not only used for central venous catheterization. The results revealed the most important clinical benefits of POCUS use by pediatric intensive care providers. Our results confirm the widespread use of POCUS in PICUs. We believe that our study is important in terms of the training status of clinicians for POCUS use. Despite the good training level and homogeneity of training status in our country, we believe that the training courses should continue to increase.

\section{Acknowledgement}

We want to thank Rafael González Cortés et al. for sharing their survey with us. This was a great contribution to our study, and we are grateful to them. We also thank the pediatric intensive care specialists in the participating units who were members of the Turkish POCUS Study Group for their collaboration in our survey. We created a list of acknowledgement by their surnames:

Hasan Ağın (Dr. Behçet Uz Children's Hospital), Ayşe Berna Anıl (İzmir Tepecik Training and Research Hospital), Eylem Alıncak (Şanlıurfa Training and Research Hospital), Gazi Arslan (Kocaeli Derince Training and Research Hospital), Ali Ertuğ Arslanköylü (Mersin University Faculty of Medicine), Ülkem Koçoğlu Barlas (Bakırköy Dr. Sadi Konuk Training and Research Hospital), Süleyman Bayraktar (Haseki Training and Research Hospital), Yasemin Çoban (Hatay State Hospital), Oğuz Dursun (Akdeniz University Faculty of Medicine), Muhterem Duyu (İstanbul Medeniyet University Göztepe Training and Research Hospital), Gökhan Kalkan (Gazi University Faculty of Medicine), Fulya Kamit (Denizli State Hospital), Murat Kangin (Diyarbakır Gazi Yasargil Training and Research Hospital), Tanıl Kendirli (Ankara University), Selman Kesici (Hacettepe University Faculty of Medicine), Halil Keskin (Atatürk University), Hasan Serdar Kihtır (Antalya Training and Research Hospital), Arda Kılınç (Diyarbakır Dağkapı State Hospital), Çapan Konca (Adıyaman University Faculty of Medicine), Tolga Köroğlu (Dokuz University Faculty of Medicine), Arzu Oto (Bursa Yuksek Ihtisas Training and Research Hospital), Çağlar Ödek (İstanbul Aydın University), Göktuğ Özdemir (Dokuz Eylül University Faculty of Medicine), Oktay Perk (Ankara City Hospital), Mey Talip Petmezci (Okmeydanı Training and Research Hospital), Ercüment Petmezci (T.C. Yeni Yüzyıl University) Şahin Sincar (Gazi University Faculty of Medicine), Murat Tanylldız (Mersin City Hospital), İlknur Tolunay (Adana City Hospital), Özlem Temel (Konya Training and Research Hospital), Emel Uyar (Marmara 
University Faculty of Medicine), Mutlu Uysal (Dr. Sami Ulus Childrens's Hospital), Nilüfer Yalındağ (Marmara University Faculty of Medicine), Pınar Yazıcı (Ege University Faculty of Medicine), Osman Yeşilbaş (Bezmialem University) Resul Yılmaz (Selçuk University), Ufuk Yükselmiş (Dr. Lütfi Kırdar Training and Research Hospital).

\section{REFERENCES}

1. Volpicelli G, Elbarbary M, Blaivas $M$, et al; International Liaison Committee on Lung Ultrasound (ILC-LUS) for International Consensus Conference on Lung Ultrasound (ICC-LUS). International evidence-based recommendations for point-of-care lung ultrasound. Intensive Care Med 2012; 38: 577-591.

2. Moore CL, Copel JA. Point-of-care ultrasonography. N Engl J Med 2011; 364: 749-757.

3. O'Brien AJ, Brady RM. Point-of-care ultrasound in paediatric emergency medicine. J Paediatr Child Health 2016; 52: 174-180.

4. Chamberlain MC, Reid SR, Madhok M. Utilization of emergency ultrasound in pediatric emergency departments. Pediatr Emerg Care 2011; 27: 628-632.

5. Lee EP, Hsia SH, Lin JJ, et al. Hemodynamic analysis of pediatric septic shock and cardiogenic shock using transpulmonary thermodilution. Biomed Res Int 2017; 2017: 3613475.

6. Conlon TW, Himebauch AS, Fitzgerald JC, et al. Implementation of a pediatric critical care focused bedside ultrasound training program in a large academic PICU. Pediatr Crit Care Med 2015; 16: 219226.

7. Kanji HD, McCallum J, Sirounis D, MacRedmond R, Moss R, Boyd JH. Limited echocardiography-guided therapy in subacute shock is associated with change in management and improved outcomes. J Crit Care 2014; 29: 700-705.

8. Longjohn M, Wan J, Joshi V, Pershad J. Point-ofcare echocardiography by pediatric emergency physicians. Pediatr Emerg Care 2011; 27: 693-696.

9. Xirouchaki N, Magkanas E, Vaporidi K, et al. Lung ultrasound in critically ill patients: comparison with bedside chest radiography. Intensive Care Med 2011; 37: 1488-1493.

10. Dubourg J, Javouhey E, Geeraerts T, Messerer M, Kassai B. Ultrasonography of optic nerve sheath diameter for detection of raised intracranial pressure: a systematic review and meta-analysis. Intensive Care Med 2011; 37: 1059-1068.
11. Dickman E, Tessaro MO, Arroyo AC, Haines LE, Marshall JP. Clinician-performed abdominal sonography. Eur J Trauma Emerg Surg 2015; 41: 4811492.

12. Lamperti $M$, Bodenham AR, Pittiruti $M$, et al. International evidence-based recommendations on ultrasound-guided vascular access. Intensive Care Med 2012; 38: 1105-1117.

13. Jauregui J, Nelson D, Choo E, et al. The BUDDY (Bedside Ultrasound to Detect Dehydratation in Youth) study. Crit Ultrasound J 2014; 6: 15.

14. Bilgili B, Haliloglu M, Tugtepe H, Umuroglu T. The assessment of intravascular volume with inferior vena cava and internal jugular vein distensibility indexes in children undergoing urologic surgery. J Invest Surg 2018: 31: 523-528.

15. Cohen JS, Teach SJ, Chapman JI. Bedside ultrasound education in pediatric emergency medicine fellowship programs in the United States. Pediatr Emerg Care 2012; 28: 845-850.

16. Marin JR, Zuckerbraun NS, Kahn JM. Use of emergency ultrasound in United States pediatric emergency medicine fellowship programs in 2011. J Ultrasound Med 2012; 31: 1357-1363.

17. Bortcosh W, Shaahinfar A, Sojar S, Klig JE. New directions in point-of-care ultrasound at the crossroads of paediatric emergency and critical care. Curr Opin Pediatr 2018; 30: 350-358.

18. Scaife ER, Fenton SJ, Hansen KW, Metzger RR Use of focused abdominal sonography for trauma at pediatric and adult trauma centers: a survey. J Pediatr Surg 2009; 44: 1746-1749.

19. Millington SJ. Cardiac ultrasound is a competency of critical care medicine. Crit Care Med 2017; 45: 15551557.

20. Klugman D, Berger JT. Echocardiography and focused cardiac ultrasound. Pediatr Crit Care Med 2016; 17 (8 Suppl 1): S222-S224.

21. Tissot C, Singh Y, Sekarski N. Echocardiographic evaluation of ventricular function-for the neonatologist and pediatric intensivist. Front Pediatr 2018; 6: 79.

22. Davis AL, Carcillo JA, Aneja RK, et al. American College of Critical Care Medicine Clinical Practice Parameters for Hemodynamic Support of Pediatric and Neonatal Septic Shock. Crit Care Med 2017; 45: 1061-1093.

23. Lambert RL, Boker JR, Maffei FA. National survey of bedside ultrasound use in pediatric critical care. Pediatr Crit Care Med 2011; 12: 655-659. 
24. Boursiani C, Tsolia M, Koumanidou C, et al. Lung ultrasound as first-line \& examination for the diagnosis of community-acquired pneumonia in children. Pediatr Emerg Care 2017; 33: 62-66.

25. Yilmaz HL, Özkaya AK, Sarı Gökay S, Tolu Kendir Ö, Şenol H. Point-of-care lung ultrasound in children with community acquired pneumonia. Am J Emerg Med 2017; 35: 964-969.

26. Soldati G, Testa A, Sher S, Pignataro G, La Sala M, Gentiloni Silveri M. Occult traumatic pneumothorax: diagnostic accuracy of lung ultrasonography in the emergency department. Chest 2008; 133: 204-211.

27. Kirkpatrick AW, Sirois M, Laupland KB, et al. Hand-held thoracic sonography for detecting posttraumatic pneumothoraces: the extended focused assessment with sonography for trauma (EFAST). J Trauma 2004; 57: 288-295.

28. Lichtenstein DA. Lung ultrasound in the critically ill. Curr Opin Crit Care 2014; 20: 315-322.

29. González Cortés R, Renter Valdovinos L, Coca Pérez A, Vazguez Martinez JL. Ecografía en el punto de cuidado en las unidades de cuidados intensivos pediátricos espanolas. An Pediatr (Barc) 2017; 86: 344-349.

30. Panebianco NL, Fredette JM, Szyld D, Sagalyn EB, Pines JM, Dean AJ. What you see (sonographically) is what you get: vein and patient characteristics associated with successful ultrasound-guided peripheral intravenous placement in patients with difficult access. Acad Emerg Med 2009; 16: 12981303.

31. Froehlich CD, Rigby MR, Rosenberg ES, et al. Ultrasound-guided central venous catheter placement decreases complications and decreases placement attempts compared with the landmark technique in patients in a pediatric intensive care unit. Crit Care Med 2009; 37: 1090-1096.

32. Shiloh AL, Savel RH, Paulin LM, Eisen LA. Ultrasound-guided catheterization of the radial artery: a systematic review and meta-analysis of randomized controlled trials. Chest 2011; 139: 524529.
33. Bhattacharjee S, Maitra S, Baidya DK. Comparison between ultrasound guided technique and digital palpation technique for radial artery cannulation in adult patients: an updated meta-analysis of randomized controlled trials. J Clin Anesth 2018; 47: 54-59.

34. Barbier C, Loubieres Y, Schmit C, et al. Respiratory changes in inferior vena cava diameter are helpful in predicting fluid responsiveness in ventilated septic patients. Intensive Care Med 2004; 30: 1740-1746.

35. Feissel M, Michard F, Faller JP, Teboul JL. The respiratory variation in inferior vena cava diameter as a guide to fluid therapy. Intensive Care Med 2004; 30: 1834-1837.

36. Geeraerts T, Merceron S, Benhamou D, Vigue B, Duranteau J. Non-invasive assessment of intracranial pressure using ocular sonography in neurocritical care patients. Intensive Care Med 2008; 34: 2062-2067.

37. Girisgin AS, Kalkan E, Kocak S, Cander B, Gül M, Semiz M. The role of optic nerve ultrasonography in the diagnosis of elevated intracranial pressure. Emerg Med J 2007; 24: 251-254.

38. Miglioretti DL, Johnson E, Williams A, et al. The use of computed tomography in pediatrics and the associated radiation exposure and estimated cancer risk. JAMA Pediatr 2013; 167: 700-707.

39. Blanco P, Buendia CM. Point-of-care ultrasound in cardiopulmonary resuscitation: a concise review. J Ultrasound 2017; 20: 193-198.

40. Atalay YO, Polat AV, Ozkan EO, Tomak L, Aygun C, Tobias JD. Bedside ultrasonography for the confirmation of gastric tube placement in the neonate. Saudi J Anaesth 2019; 13: 23-27.

41. Gok F, Kilicaslan A, Yosunkaya A. Ultrasoundguided nasogastric feeding tube placement in critical care patients. Nutr Clin Pract 2015; 30: 257-260.

42. Conlon TW, Kantor DB, Su ER, et al. Diagnostic bedside ultrasound program development in Pediatric Critical Care Medicine: results of a National Survey. Pediatr Crit Care Med 2018; 19: e561-e568. 